\title{
Hydroxamic Acids
}

National Cancer Institute

\section{Source}

National Cancer Institute. Hydroxamic Acids. NCI Thesaurus. Code C556.

A group of weak acids with the general chemical formula $\mathrm{RC}(=\mathrm{O}) \mathrm{N}\left(\mathrm{R}^{\prime}\right) \mathrm{OH}$ and antineoplastic and antimicrobial activities. Hydroxamic acids covalently bind to the zinc(II) ion in the active sites of matrix metalloproteinases (MMP), thereby inhibiting the action of MMPs, inducing extracellular matrix degradation, and inhibiting angiogenesis, tumor growth and invasion, and metastasis. ( $\mathrm{NCl04)}$ 